\title{
Transitioning from batch to flow hypersaline microbial fuel cells
}

\author{
Stuart J. Robertson ${ }^{\mathrm{a}, 1}$, Matteo Grattieri ${ }^{\mathrm{b}, ~}{ }^{*}, 1$, Julia Behring ${ }^{\text {b, c }}$, Massimiliano Bestetti ${ }^{\text {c }}$ \\ Shelley D. Minteer ${ }^{b}$ \\ a Chemical Engineering Department, University of Utah, 50 Central Campus Dr, Salt Lake City, UT, 84112, USA \\ ${ }^{\mathrm{b}}$ Departments of Chemistry and Materials Science \& Engineering, University of Utah, 315 S 1400 E Rm 2020, Salt Lake City, UT, 84112, USA \\ ${ }^{\mathrm{c}}$ Department of Chemistry, Materials and Chemical Engineering “G. Natta”, Politecnico di Milano, Piazza L. da Vinci 32, 20133, Milano, Italy
}

\section{A R T I C L E I N F O}

\section{Article history:}

Received 9 April 2019

Received in revised form

10 May 2019

Accepted 1 June 2019

Available online 3 June 2019

\section{Keywords:}

Flow microbial fuel cell

Hypersaline solution

Extracellular electron transfer

Self-powered biosensor

Chemical oxygen demand

\begin{abstract}
A B S T R A C T
Application of electro-active halotolerant bacteria in bioelectrochemical systems opens for the sustainable on line monitoring of saline wastewater treatment; however, this approach has been investigated only in lab-scale devices, mostly in batch configuration. The field application of the technology introduces several parameters that can influence bioelectrochemical and degradation performance. Herein, we report the detailed study of how continuous flow operation $\left(3 \pm 1 \mathrm{~mL} \mathrm{~min}^{-1}\right)$ affects the bioelectrochemical performance of a flow hypersaline microbial fuel cell. Flow operation resulted in a 70\% decrease of power density (passing from $2.1 \pm 0.1$ to $0.67 \pm 0.01 \mathrm{~mW} \mathrm{~m}^{-2}$ ), where the washout of endogenous redox mediator played a critical role. Engineering of bacteria entrapment techniques mitigated the inhibitory effects of continuous flow, ensuring successful extracellular electron transfer. Specifically, bacteria entrapment in composite alginate capsules with activated carbon to enhance their conductivity was investigated, and the effects of different activated carbon loads are presented. A maximum power density comparable to batch operation was achieved for composite capsules with 0.15 $\mathrm{gL}^{-1}$ activated carbon $\left(1.8 \pm 0.9 \mathrm{~mW} \mathrm{~m}^{-2}\right)$, as well as the possible correlation of electrochemical and COD removal performance, enabling future development of self-powered hypersaline flow microbial biosensor for contaminants monitoring.
\end{abstract}

(C) 2019 Elsevier Ltd. All rights reserved.

\section{Introduction}

Saline and hypersaline wastewater (total dissolved salt content between 1 and 3.5\%, and higher than $3.5 \% \mathrm{v} / \mathrm{w}$, respectively) is a quite common by-product of several industries, such as the chemical, agro-food, oil \& gas, and leather industries among others [1]. As a consequence, an enormous amount of saline wastewater is produced worldwide accounting for $5 \%$ of the total wastewater generated (approximately 100 trillion liters yearly) [2,3]. While classical aerobic biological treatments are not suitable for such solutions, due to the inhibition effects that high salinity has on the activity of bacterial species [4], application of halotolerant bacteria, which tolerate moderate to high salinity, has been explored, with promising results for bioremediation of oil spills in salt marshes $[5,6]$. Exposure time and adaptation of microorganisms to saline environments is a critical aspect for successful bioremediation,

\footnotetext{
* Corresponding author.

E-mail address: matteo.grattieri@utah.edu (M. Grattieri).

1 Both authors contributed equally.
}

although results are different for various microbial consortia, and reports can be found with no contaminants degradation even after long exposure times [7]. A better understanding of the adaptation strategies utilized by bacterial cells could allow tuning their salttolerance [8]. In this context, monitoring contaminant levels in such high saline solutions is critical, to avoid the release of toxic compounds in the environment. Collecting samples and performing laboratory analyses is the classical approach for the monitoring of the decontamination process. However, these analyses are time consuming and generate toxic wastes as $\mathrm{Cr}$ solutions are utilized. The combination of microbial metabolism with an electrochemical system has been investigated for the self-sustained treatment and monitoring of wastewater [9]. Bacteria capable of exchanging electrons with an electrode surface, by a process called extracellular electron transfer (EET)[10-13], can be applied in microbial fuel cells (MFCs), and the generated electrical current can be correlated to the removal of organic contaminants, opening for the development of self-powered microbial biosensor [14-16]. However, similarly to the inhibition of microbial activity, high salinity was reported to affect the electrochemical performance of MFCs from as 
low as a total salt content of $15-20 \mathrm{gL}^{-1}$ [17]. Inspired by the successful application of halotolerant bacteria for saline wastewater treatment, research efforts have been focused on unveiling their bioelectrocatalytic properties in MFCs [18-20]. The possibility to operate MFCs with these organisms was reported for solutions with salinities higher than $100 \mathrm{gL}^{-1}$ [21,22]. It is important to note that, compared to MFCs operating in optimal conditions in terms of electro-active bacteria, $\mathrm{pH}$, low salinity, and electrolyte composition, the power densities and coulombic efficiencies achieved with hypersaline MFCs are considerably lower, mostly due to the additional energy required by bacterial cells to balance the osmotic pressure in such extremely saline solutions [23]. Moreover, detailed information on EET processes remains limited[11,13], particularly for halotolerant microorganisms [24]. Better understanding of EET could strongly enhance bioelectrocatalytic performance, making the application of MFCs for saline solution monitoring appealing. Our group has isolated a halotolerant strain of Salinivibrio sp. from the Great Salt Lake (Utah), named Salinivibrio EAGSL, and showed its potential application in batch MFC for current production during organic removal in hypersaline solutions [25,26]. Furthermore, encapsulation of bacterial cells in alginate capsules utilized in a Lshape single chamber microbial fuel cell operated in batch conditions allowed stable performance of the device over the duration of long-term operation ( $>5$ months), and the possible correlation between electrical current production and concentration of organic substrates was reported [15], opening up for the development of self-powered hypersaline biosensors [16]. Several aspects require further elucidation in order to scale up the technology for application in the field, where the majority of biological treatment plants operate in continuous mode. Specifically, cost-effective and robust electrode materials will be required, and the device will have to withstand high daily load of solutions to be monitored. Accordingly, the operation of the bioelectrochemical systems in continuous flow, rather than in batch mode, is critical. However, operating in continuous flow can affect the extracellular electron transfer between bacterial cells and electrode surfaces. Furthermore, the decreased contact time between dissolved organic compounds and bacterial cells could potentially decrease bioelectrochemical performance. All these aspects would result in a reduced current generation of the hypersaline MFC, affecting its capability to operate as a self-powered microbial biosensor for the decontamination process. Due to the lack of detailed studies of these aspects, we aimed to investigate flow influence on bioelectrocatalysis of halotolerant bacteria. Accordingly, we developed microbial fuel cell apparatus capable of simulating continuous flow, which were operated at a total salt content $>100 \mathrm{gL}^{-1}$ with a flow rate of $3 \pm 1 \mathrm{~mL} \mathrm{~min}^{-1}$. The entrapment of bacterial cells in alginate capsules previously developed by our group was utilized for enhanced stability and to avoid loss of bacteria due to the applied flow. Furthermore, we explored the modification of alginate capsules, utilizing different activated carbon loads $\left(0.15\right.$ and $\left.0.5 \mathrm{gL}^{-1}\right)$ to determine the effects on bioelectrocatalysis and stability of the system. Flow operation strongly affected bioelectrocatalytic performance; however, the negative effects of flow operation were overcome by careful engineering of bacteria cell entrapment, posing the basis for future development of self-powered hypersaline flow microbial biosensors for on line monitoring of saline wastewater decontamination.

\section{Materials and methods}

\subsection{Chemicals}

All chemicals were obtained from Sigma-Aldrich, except $\mathrm{KH}_{2} \mathrm{PO}_{4}, \mathrm{NH}_{4} \mathrm{Cl}$ (Macron Chemicals), $\mathrm{Na}_{2} \mathrm{SO}_{4}$, sodium acetate trihydrate (Fisher Chemicals), NaCl (VWR Analytical), and carbon black (Alfa Aesar). Norit SX Ultra activated carbon (AC) from SigmaAldrich was used to prepare composite alginate capsules and cathodes of the MFCs.

\subsection{Bacteria culture}

Salinivibrio sp. EAGSL was previously isolated from a mixture of bacterial samples collected from the Great Salt Lake [27]. Based on the sulfate-reducing metabolism of EAGSL, a sulfate-reducing medium (SRB) was utilized for cell growth, as previously reported $[25,26]$. The final composition, per Liter of de-ionized water, is: $0.5 \mathrm{~g} \mathrm{KH}_{2} \mathrm{PO}_{4}, 1 \mathrm{~g} \mathrm{NH}_{4} \mathrm{Cl}, 1 \mathrm{~g} \mathrm{Na}_{2} \mathrm{SO}_{4}, 1 \mathrm{~g} \mathrm{CaCl}_{2}, 1.83 \mathrm{~g} \mathrm{MgCl}^{*} 6 \mathrm{H}_{2} \mathrm{O}, 1 \mathrm{~g}$ yeast extract, $0.1 \mathrm{~g}$ ascorbic acid, $0.013 \mathrm{~g}$ sodium thioglycolate, $6.38 \mathrm{~g}$ sodium citrate, $0.5 \mathrm{~g} \mathrm{FeSO}_{4}{ }^{*} 7 \mathrm{H}_{2} \mathrm{O}, 1.75 \mathrm{~g}$ sodium lactate, $2 \mathrm{~g}$ sodium acetate trihydrate, and $10 \% \mathrm{NaCl}(100 \mathrm{~g})$. The $\mathrm{pH}$ of the solution was adjusted between 7.5 and 8 using a concentrated $\mathrm{NaOH}$ solution. Prior to bacteria inoculation, the growth medium was sterilized at $121^{\circ} \mathrm{C}$ for $25 \mathrm{~min}$ (Getinge Group Steam Sterilizer). Calcium chloride and iron sulfate were added after sterilization, by filtration through a $0.20 \mu \mathrm{m}$ filter (VWR International). Growth of EAGSL was started by transferring cells from glycerol stocks stored at $-80^{\circ} \mathrm{C}$ to $7 \mathrm{~mL}$ of SRB medium incubated at $30^{\circ} \mathrm{C}$ and $180 \mathrm{rpm}$ for $24 \mathrm{~h}$. The growth was then transferred in a $250 \mathrm{~mL}$ sterile flask, with a 1:10 vol ratio of bacterial growth and fresh SRB medium respectively, and incubated under the same conditions for $24 \mathrm{~h}$.

\subsection{Preparation of alginate capsules and composite alginate capsules}

The entrapment of EAGSL cells into alginate capsules was performed following a procedure previously reported [28]. Specifically, a 1:1 vol ratio of alginate and bacterial growth was obtained by using a solution of $30 \mathrm{gL}^{-1}$ alginic acid previously sterilized by boiling. The resulting mixture was dropped using a syringe pump (Pump 11 Elite, Harvard Apparatus) into a $30 \mathrm{gL}^{-1}$ calcium chloride solution to obtain the alginate capsules. The capsules were then washed with deionized water to remove any residuals of calcium chloride.

Modification of the alginate capsules was performed using two different loads of activated carbon (AC), 0.15 and $0.5 \mathrm{gL}^{-1}$. The composite capsules were obtained by adding the desired amount of AC to the alginic acid solution prior the sterilization step performed at boiling temperatures.

\subsection{Flow cell construction}

A schematic of the manufactured devices is reported in Fig. 1. The body of the flow cell was manufactured by cutting acrylic panels (Professional Plastics) with a laser cutter (Epilog Fusion $120 \mathrm{~W}$ ) into pieces that were assembled and sealed using silicone adhesive. The device was equipped with an air-breathing cathode prepared by mixing AC, carbon black, and poly (tetrafluoroethylene) with final weight percentage of 70,10 , and $20 \%$, respectively, on a stainless steel mesh (McMaster-Carr, Robbinsville, BJ, USA) following a previously reported procedure [29,30]. The cathode was mounted at the opening of the flow MFC using silicone. The anode electrode was made of unmodified carbon cloth (nonwet-proofed, E-TEK) connected to a copper wire with a conductive silver epoxy paste (Electron Microscopy Sciences, Hatfield, USA). The electrical connection was insulated by at least five layers of nonconductive epoxy resin (ITW Devcon, Danvers, USA). During operation, the anode was maintained at a distance of $2.0 \pm 0.5 \mathrm{~cm}$ from the cathode. Inlet and outlet for the designed flow cell were obtained by connecting a closed circuit of 1/32" ID tubing (Tygon S3 


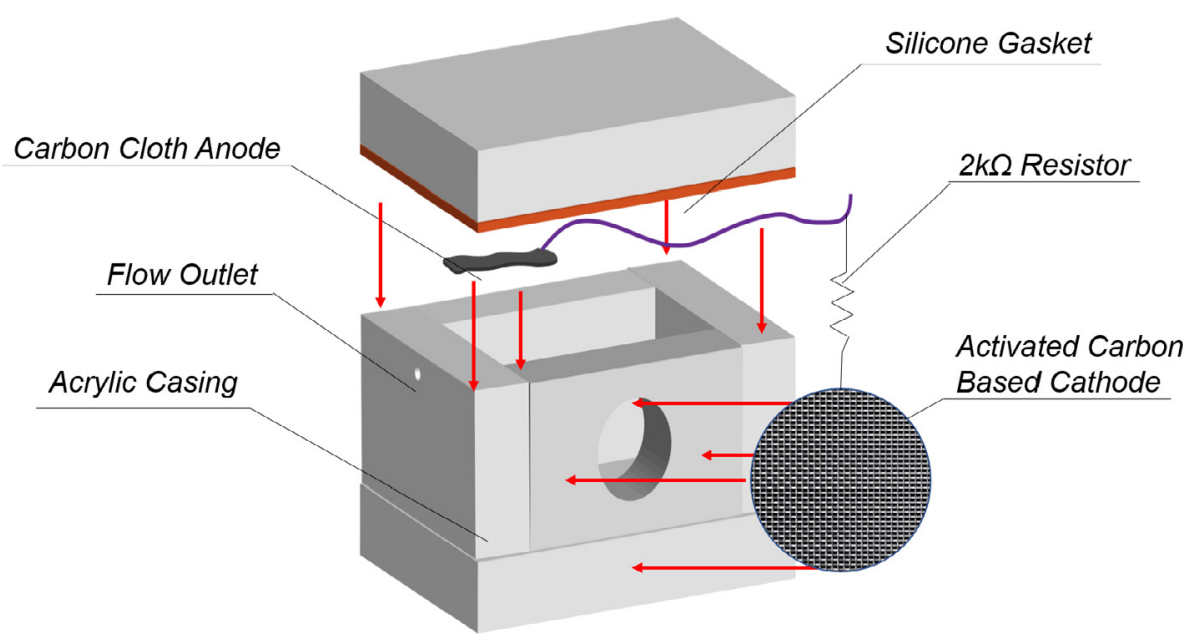

Fig. 1. Schematic of the flow-microbial fuel cells constructed.

E-LFL) and to a peristaltic pump (Mini-Pump Variable Flow 0.4 to $85 \mathrm{mLmin}^{-1}$, Fisher Scientific) for a final flow rate of $3 \pm 1 \mathrm{~mL} \mathrm{~min}^{-1}$. The MFCs were filled with $75 \mathrm{~mL}$ of fresh media and $35 \mathrm{~mL}$ of EAGSL-alginate capsules prepared as previously described.

\subsection{Electrochemical setup}

At least three independent replicate experiments were performed for all the electrochemical characterizations, by operating multiple MFCs. The average values for power and current densities are reported, together with their standard deviations. A $2000 \Omega$ load was utilized to close the electrical circuit between the anode and the cathode of flow-MFCs during their operation. The microbial fuel cells were operated at a temperature of $20 \pm 2{ }^{\circ} \mathrm{C}$, and the difference of potential between the two electrodes was monitored every 10 min using a computer-controlled multimeter (USB-1608G, measurement Computing). For the control experiments, the sterile SRB media (autoclaved at $121^{\circ} \mathrm{C}$ for $15 \mathrm{~min}$ ) and sterile electrodes (autoclaved at $121^{\circ} \mathrm{C}$ for $25 \mathrm{~min}$ ) were utilized to set up MFCs operated under the conditions described above.

Electrochemical performance of the anodes of MFCs in different configurations were then evaluated by plotting quasi-stationary polarization curves (CH660 potentiostat) by using a threeelectrode set up with the anode as the working electrode (WE), Pt mesh as a counter electrode (CE), and the saturated calomel electrode (SCE) as reference electrode (RE), at a scan rate of $0.2 \mathrm{mV} \mathrm{s}^{-1}$. The polarizations are shown following the polarographic convention. Electrical power curves were obtained from the quasi-stationary polarization curves ( $\mathrm{CH} 660$ potentiostat) performed at a scan rate of $0.1 \mathrm{mV} \mathrm{s}^{-1}$, in which the cathode was used as WE, and the anode as CE and RE. Before any electrochemical experiment (power curves or quasi-stationary polarizations), the MFCs were maintained under open-circuit conditions, while maintaining the flow rate, for at least $30 \mathrm{~min}$ to ensure stabilization of the system and avoid erroneous evaluations. The power density $(P)$ was calculated as the potential $(E)$ times the current density $(j)$, based on anode surface area $\left(4.5 \mathrm{~cm}^{2}\right)$. Evolution of the open circuit potentials for the electrodes of the MFCs was also recorded. All the reported potentials in the manuscript refer to SCE reference electrode. Scanning electron microscopy was performed with a FEI Quanta 600 FEG microscope to study the surface of the anodes after operation in flow MFCs utilizing composite alginate capsules with 0.15 and $0.5 \mathrm{gL}^{-1} \mathrm{AC}$.

\subsection{Chemical oxygen demand (COD) monitoring}

Evolution of the COD throughout the degradation cycles was monitored by using the Ultra High Range TNTplus Vial Test (Hach, Loveland, USA), following the manufacturer's instructions. Samples were diluted tenfold with Milli-Q water to lower the $\mathrm{NaCl}$ concentration to $10 \mathrm{gL}^{-1}$ before analysis (maximum concentration to avoid interference in the analysis). The COD evolution was monitored for at least three independent replicate experiments, and average values are reported, together with their standard deviations. Finally, the average coulombic efficiency $(C E)$ was calculated by comparing the current levels exhibited by the MFCs and the COD variation during a 5 days period. The coulombic charge that passed through the $2000 \Omega$ load was estimated by trapezoidal integration of the current-time trends. CE was calculated as (eq. (1)):

$C E=\frac{M \int_{0}^{5 \text { days }} I d t}{n F v \triangle C O D}$

where $M$ is the molecular weight of oxygen $\left(32 \mathrm{~g} \mathrm{~mol}^{-1}\right), n$ represents the number of electrons exchanged per mole of oxygen (4), $F$ is the Faraday's constant $(96,485 \mathrm{C}), v$ indicates the volume of the MFCs $(0.1 \mathrm{~L})$ and $\triangle C O D$ indicates the change in COD over the 5 days period in $\mathrm{g}_{\mathrm{O} 2} \mathrm{~L}^{-1}$.

\section{Results and discussion}

\subsection{Electrochemical performance}

Comparison of the electrochemical performance for the different setups of MFCs during the first degradation cycle was first investigated by anodic quasi-stationary polarizations, as shown in Fig. 2. From the results, the data showed that composite alginate capsules with 0.15 and $0.5 \mathrm{gL}^{-1}$ activated carbon (red and purple, respectively) shifted the open circuit potential to more negative values $(-180 \pm 80$ and $-160 \pm 40 \mathrm{mV})$ compared to the anodes operating in batch and flow MFCs with alginate capsules $(-100 \pm 30$ and $-60 \pm 30 \mathrm{mV}$, respectively). The potential shift could be due to the enhanced conductivity of the alginate capsules and the capability of activated carbon to adsorb substrate (sodium acetate), thus limiting oxygen from reaching entrapped bacterial cells. Moreover, the composite capsules allowed current densities 


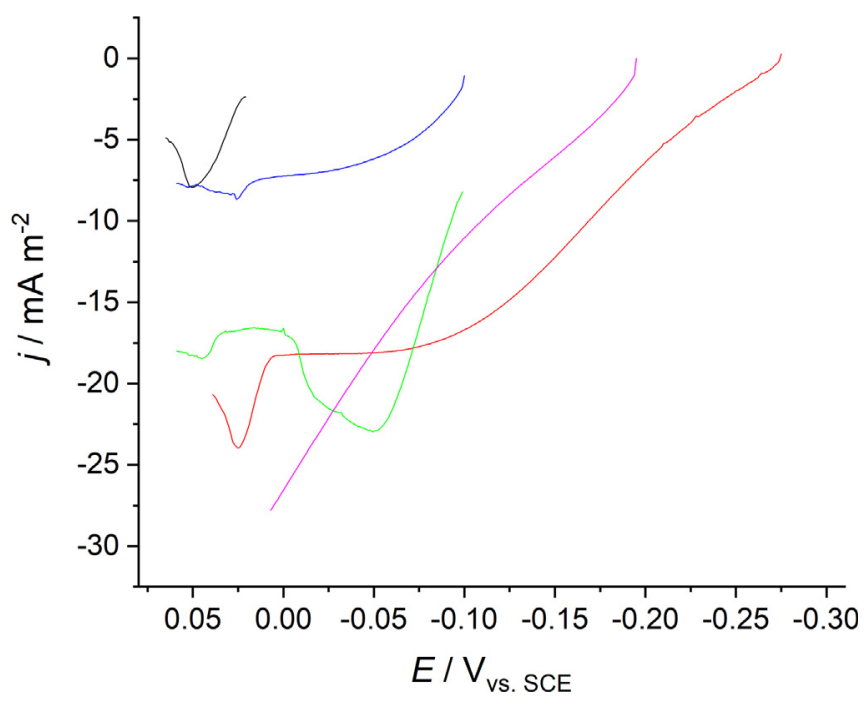

Fig. 2. Representative anodic quasi-stationary polarizations for the anode of batch (green), flow (blue), flow MFC with 0.15 (red), and $0.5 \mathrm{gL}^{-1} \mathrm{AC}$ composite alginate capsules (purple) obtained during the first degradation cycle. Control experiments were performed in sterile conditions (black, sterile composite capsules with AC). Scan rate $0.2 \mathrm{mV} \mathrm{s}^{-1}$. Counter electrode Pt. Reference electrode SCE.

similar to those obtained for MFCs operated in batch conditions $\left(-20 \pm 5\right.$ and $-25 \pm 3 \mathrm{mAm}^{-2}$ at $-0.05 \mathrm{~V}$, respectively), while flowMFC with alginate capsules showed limited current densities $\left(-8 \pm 2 \mathrm{mAm}^{-2}\right.$ at $\left.-0.05 \mathrm{~V}\right)$. It can be noted that a redox peak was obtained for batch MFC, at approximately $-0.05 \mathrm{~V}$. The redox peak could be related to an endogenous redox mediator secreted by bacterial cells that facilitate the extracellular electron transfer, as suggested in our previous studies [27]. The redox peak is absent or less pronounced when the MFCs are operated in flow mode, possibly due to a washout of the mediator caused by the flow rate. Accordingly, the alginate capsules with both activated carbon loads utilized facilitated the extracellular electron transfer process during the first degradation cycle, limiting the negative effects due to flow conditions. The control experiments showed very positive open circuit potentials, as well as low current densities, confirming the role of microbial bioelectrocatalysis for the obtained current responses. A redox peak was obtained at positive potentials (between +0.025 and $+0.060 \mathrm{~V}$ ) for both control MFCs and MFCs with bacterial cells. The obtained current response could be due to the direct oxidation on the electrode surface of chemicals present in the electrolytic solution.

In view of a self-powered biosensor development, it is of the utmost importance to further elucidate the effects of decreasing concentrations of organic compounds on anode performance. Accordingly, quasi-stationary anodic polarizations at different degradation times were carried out. Specifically, representative polarizations for the anode of batch MFCs at 24, 96, and $120 \mathrm{~h}$ of operation (Fig. $3 \mathrm{~A}$, blue, green, and red lines, respectively), and for flow MFCs with composite capsules with 0.15 and $0.5 \mathrm{gL}^{-1} \mathrm{AC}$ at 24, 96 , and $144 \mathrm{~h}$ of operation (Fig. $3 \mathrm{~B}$ and C, blue, green, and red lines, respectively) were performed. The low current densities obtained for flow MFCs with alginate capsules make the comparison of polarizations at different degradation times difficult, and thus are not reported here. It can be noted that both batch and flow MFCs with $0.15 \mathrm{gL}^{-1} \mathrm{AC}$ showed decreasing current responses for longer operational times. Moreover, a redox peak at potentials between -0.05 and $0.0 \mathrm{~V}$ could be obtained in batch MFCs even after $120 \mathrm{~h}$ of operation, while the peak completely disappeared for flow MFCs. This result further suggests that a washout of a soluble redox mediator is responsible for the different performance between batch and flow MFCs with regular alginate capsules, hindering the extracellular electron transfer. The results obtained for quasi-stationary anodic polarization in MFCs operated with composite capsules with $0.5 \mathrm{gL}^{-1} \mathrm{AC}$ deserve a different discussion. It can be noted that after $96 \mathrm{~h}$ of operation a marked redox peak was obtained, at a potential similar to batch MFCs. The redox peak obtained at this operational time could be due to a mechanical instability of the composite alginate capsules resulting from the higher AC content. Additionally, the adsorption characteristic of AC for organic compounds could result in a higher amount of solution entering the capsules, leading to their failure and the consequent washout of trapped redox mediator. A mechanical instability of the composite capsules prepared with $0.5 \mathrm{gL}^{-1} \mathrm{AC}$ is supported also by the evolution of the degradation performance discussed below. Furthermore, to confirm this hypothesis we performed scanning electron microscopy of the anodes utilized in flow MFCs with composite capsules prepared with 0.15 and $0.5 \mathrm{gL}^{-1} \mathrm{AC}$ (Fig. 4) after the third degradation cycle.

It can be easily noted that biofilm was developed on the anode utilized in the flow MFC operating with composite alginate capsules prepared with $0.5 \mathrm{gL}^{-1} \mathrm{AC}$ (Fig. $4 \mathrm{~A}$ ), while no particular biofilm formation was obtained in a MFC that was operated with composite alginate capsules prepared with $0.15 \mathrm{gL}^{-1} \mathrm{AC}$ (Fig. 4 B). This result provides additional evidence of the instability of composite capsules with $0.5 \mathrm{gL}^{-1} \mathrm{AC}$ previously discussed.

The power density curves for batch, flow, flow MFCs with 0.15 , and $0.5 \mathrm{gL}^{-1} \mathrm{AC}$ composite capsules are shown in Fig. 5 (green, blue, red, and purple lines, respectively). As previously seen for the anodic quasi-stationary polarizations, flow operation drastically reduced the power density, passing from $2.1 \pm 0.1 \mathrm{mWm}^{-2}$ obtained for the batch MFC to $0.67 \pm 0.01 \mathrm{mWm}^{-2}$ for flow-MFC. However, the composite capsules with $0.15 \mathrm{gL}^{-1}$ AC showed enhanced electrochemical performance, by reaching power densities comparable to the operation in batch configuration $(1.8 \pm 0.9$ $\mathrm{mWm}^{-2}$ ). MFCs with composite capsules containing $0.5 \mathrm{gL}^{-1} \mathrm{AC}$ showed a slightly lower power output, reaching $1.2 \pm 0.8 \mathrm{mWm}^{-2}$. It is interesting to note that a higher dispersion of power density values was obtained for all the MFCs operating with composite capsules. While considerable variability of current and power outputs for saline microbial anodes and MFCs in saline solutions was previously reported[18,19,31], the non-uniform distribution of activated carbon in the alginic acid solution, as well as the mechanical instability of the capsules at high AC content, might have further contributed to the scattered values obtained in this study. However, despite the significant deviations from one replicate to the other, a consistent trend was observed for composite alginate capsules, with power densities statistically comparable to MFCs operating in batch. Future optimization of the preparation technique for composite capsules could help in reducing the dispersion of the results. Comparison of the obtained power densities with reported values is complicated, as different cells configuration, electrode materials, use of projected surface areas of electrodes with various geometries (I.e. brush electrodes), and operational conditions strongly influence bioelectrochemical performance and their evaluation [23]. However, power densities reported for MFCs in hypersaline conditions with Pt-free electrodes and no exogenous redox mediators range between 0.5 and $50 \mathrm{mWm}^{-2}$ [25,27,32-37], showing the current results fall in the average values reported. It is critical to point out that the aim of the present study is not to maximize power density by operating the MFCs in their optimal condition, but, on the contrary, to resemble real operating conditions for hypersaline wastewater treatment, and to determine the effects of such conditions on bioelectrocatalysis to develop selfpowered hypersaline flow microbial biosensors. 

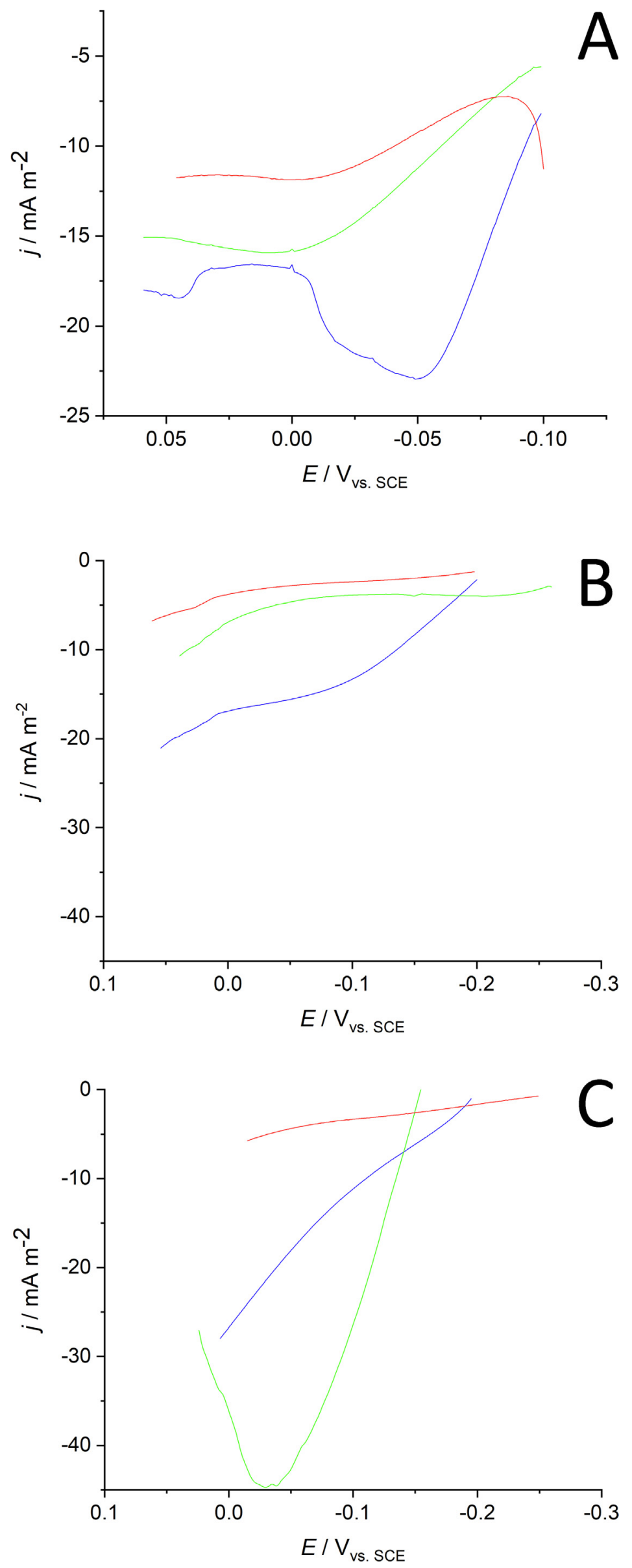

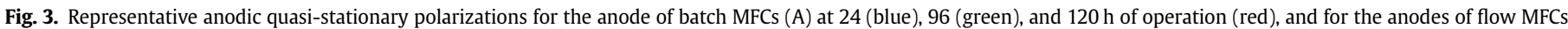

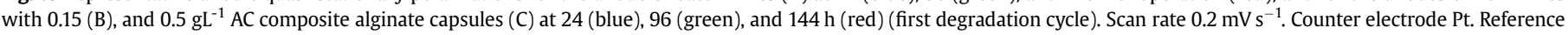
electrode SCE. 

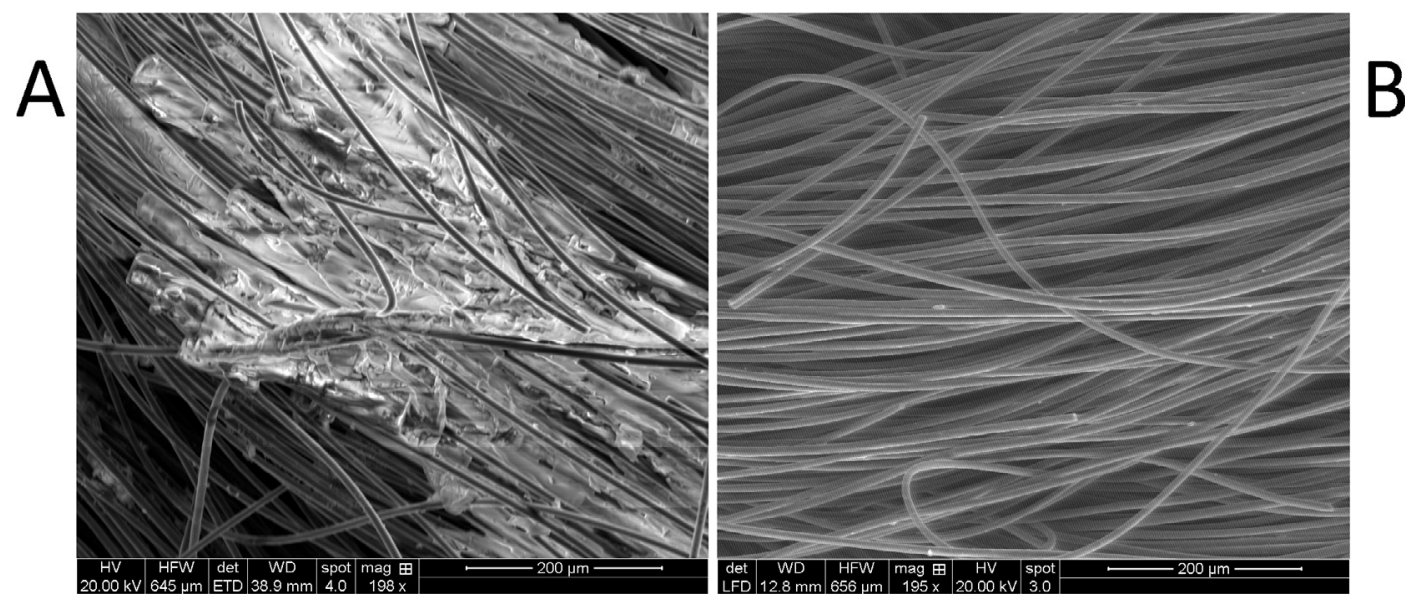

Fig. 4. Scanning electron microscopy images for an anode utilized in a flow MFC using composite alginate capsules prepared with 0.5 (A) and 0.15 gL ${ }^{-1}$ AC (B).

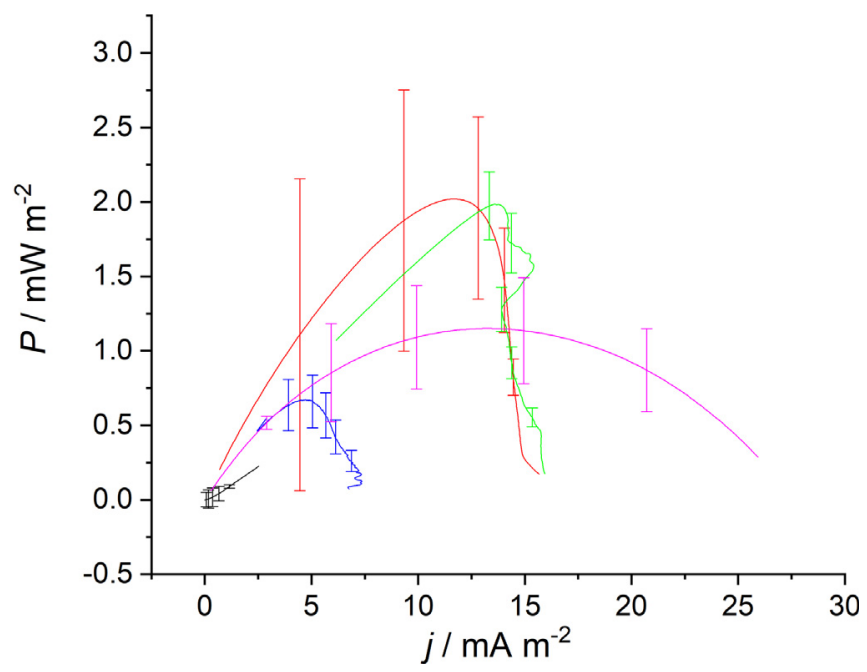

Fig. 5. Power curves for batch (green), flow (blue), and flow MFC with 0.15 (red), and $0.5 \mathrm{gL}^{-1} \mathrm{AC}$ composite alginate capsules (purple) obtained during the first degradation cycle. Control experiments were performed in sterile conditions (black, sterile electrodes, capsules, and electrolyte). Scan rate $0.1 \mathrm{mV} \mathrm{s}^{-1}$. Working electrode: cathodes, counter and reference electrodes: anodes. Three independent replicate experiments were performed and error bars indicate standard deviation.

The evolution of power densities over different degradation cycles is reported in Table 1 . It can be noted that electrochemical performance was strongly affected over time for all flow MFCs, with power output decreasing to $0.4 \pm 0.1 \mathrm{mWm}^{-2}$ also in the case of flow MFCs with different AC contents composite alginate capsules. On the contrary, batch MFC showed stable performance over the degradation cycles. The marked difference between batch and flow MFCs could be due to the decreased stability of alginate capsules introduced by the flow operation. Specifically, as previously introduced, the presence of AC could further decrease the mechanical stability of the capsules over time, leading to a washout of bacterial cells and to the presented trend of power output. Accordingly, the developed system will require further optimization to maximize the stability of composite capsules and to maintain maximum activity of the bacterial cells, allowing stable performance over longterm operation of the flow MFCs.

\subsection{Chemical oxygen demand evolution}

The evolution of chemical oxygen demand and its removal percentage for batch, flow, flow MFCs with 0.15 and $0.5 \mathrm{gL}^{-1} \mathrm{AC}$ composite capsules are reported in Fig. 6. For this study, high COD values were utilized, which are common for saline wastewater originated from oil and agro-food industries. During the first degradation cycle, similar COD evolution was obtained for batch and flow MFCs (no AC), passing from an initial value of $8000 \pm 900$ $\mathrm{mg}_{\mathrm{O} 2} \mathrm{~L}^{-1}$ to $5600 \pm 600 \mathrm{mg}_{\mathrm{O} 2} \mathrm{~L}^{-1}$ and $5800 \pm 600 \mathrm{mg}_{\mathrm{O} 2} \mathrm{~L}^{-1}$, respectively, corresponding to COD removals of approximately $30 \%$. It should be noted that the flow MFCs with $0.15 \mathrm{gL}^{-1} \mathrm{AC}$ composite capsules decreased COD to $3500 \pm 400 \mathrm{mg}_{2} \mathrm{~L}^{-1}$ (approximately $50 \%$ removal), and slightly lower removal was obtained for MFCs with $0.5 \mathrm{gL}^{-1} \mathrm{AC}$ composite capsules. When analyzing the second degradation cycle, it can be noted that the batch MFCs showed a drastic decrease in their COD removal capability after feeding them with new substrate (second and third degradation cycles, removal below 20\%). Conversely, flow MFCs maintained their removal performance, and flow MFCs with $0.15 \mathrm{gL}^{-1}$ AC composite capsules settled their removal at approximately $40 \%$. On the contrary, flow MFCs with $0.5 \mathrm{gL}^{-1} \mathrm{AC}$ showed a drastic decrease of removal performance with time, and a significant higher variability of the performance. This result correlates well with the evolution of the anodic quasi-stationary polarizations previously discussed, further motivating our interest in developing self-powered hypersaline flow microbial biosensors.

The mechanical instability of the composite capsules induced by the higher content of AC led to the failure of the system during the third degradation cycle. When the MFCs where operated in flow conditions with mechanically stable alginate capsules (flow MFC

Table 1

Evolution of power densities during three degradation cycles for batch, flow, and flow MFCs with composite capsules (0.15 and $0.5 \mathrm{gL}^{-1}$ activated carbon).

\begin{tabular}{|c|c|c|c|c|}
\hline Degradation cycle & Batch MFC (no AC) $/ \mathrm{mWm}^{-2}$ & Flow MFC (no AC) $/ \mathrm{mWm}^{-2}$ & Flow MFC with $0.15 \mathrm{gL}^{-1} \mathrm{AC} / \mathrm{mWm}^{-2}$ & Flow MFC with $0.5 \mathrm{gL}^{-1} \mathrm{AC} / \mathrm{mWm}^{-2}$ \\
\hline 1 & $2.1 \pm 0.1$ & $0.67 \pm 0.01$ & $1.8 \pm 0.9$ & $1.2 \pm 0.8$ \\
\hline 2 & $2.3 \pm 0.3$ & $0.35 \pm 0.09$ & $0.5 \pm 0.2$ & $1.2 \pm 0.9$ \\
\hline 3 & $1.6 \pm 0.2$ & $0.4 \pm 0.3$ & $0.4 \pm 0.1$ & $0.9 \pm 0.7$ \\
\hline
\end{tabular}



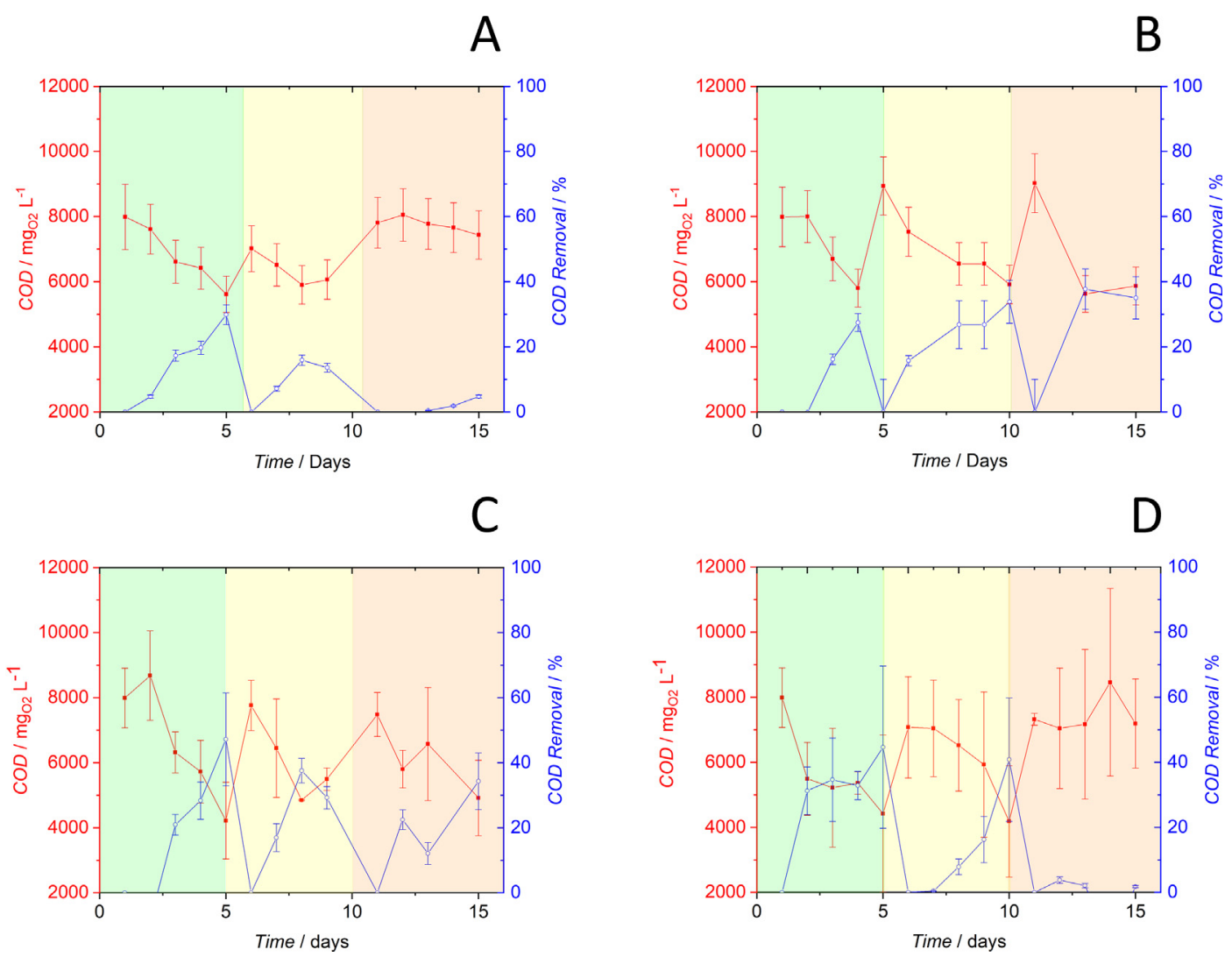

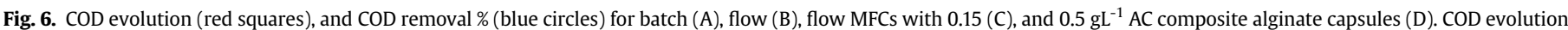

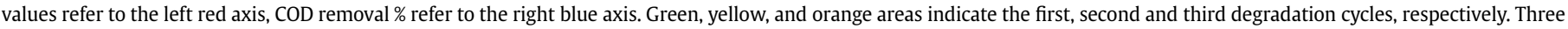
independent replicate experiments were performed and error bars indicate standard deviation.

and composite capsules with $0.15 \mathrm{gL}^{-1} \mathrm{AC}$ ), the better degradation performance could be explained with the enhanced mass transport introduced by the bulk flow, which might then facilitate diffusion of the organic species into the alginate capsules. Moreover, the adsorption properties of activated carbon[38,39], could contribute to the removal of organics as well as enhance the contact time between organic compounds and bacterial cells, leading to the improved COD removal achieved. By considering the trend of power outputs previously discussed together with the COD removal trends presented, it can be stated that while MFCs operating in batch conditions retained good bioelectrochemical performance throughout different degradation cycles, the absence of flowing conditions decreased the diffusion of organic substrates to entrapped bacterial cells, limiting the final degradation. Finally, it is important to note that average coulombic efficiency for the MFCs over a five-day period were generally low, with $0.05 \%$ for batch MFC, $0.03 \%$ for flow MFC, $0.02 \%$ for MFC with $0.15 \mathrm{gL}^{-1} \mathrm{AC}$ composite capsules, and $0.03 \%$ for MFC with $0.5 \mathrm{gL}^{-1} \mathrm{AC}$ composite capsules. While batch MFCs obtained the highest CE, it should be considered that flow MFCs with composite capsules achieved the highest COD removal, thanks to the adsorption capability of AC, which could have accounted for the removal of organic compounds not utilized in the microbial metabolism of Salinivibrio EAGSL.

The obtained values indicate that a consistent part of the degradation was not related with an electrode-respiring metabolism of the bacterial cells. This result is expected in hypersaline solutions, since microorganisms must utilize energy to maintain their intracellular osmolarity [40]. However, it is important to underline that while current densities and power generation might be low, the study of bioelectrocatalysis in flow systems operating with hypersaline solutions is of particular interest in view of developing microbial biosensor for the sustainable on line continuous monitoring of the decontamination process.

\section{Conclusions}

The development of flow-MFCs for application as self-powered hypersaline microbial biosensor is fundamental to implement the technology for on-line monitoring of saline solutions. In this contest, it is critical to understand the effects of flow operation on the extracellular electron transfer process of halotolerant bacteria. The flowing operating conditions caused a washout of a soluble redox mediator, hindering the extracellular electron transfer, which resulted in a $70 \pm 20 \%$ reduction of bioelectrocatalytic performance (based on power output). The replacement of alginate capsules with composite alginate capsules containing activated carbon facilitated the electron transfer between the entrapped bacteria and the electrode surface, allowing achievement of bioelectrochemical performances similar to those obtained in batch conditions. While $0.5 \mathrm{gL}^{-1}$ of AC maximized the extracellular electron transfer, the mechanical stability of the composite capsule was compromised compared to capsules containing $0.15 \mathrm{gL}^{-1} \mathrm{AC}$, resulting in the higher dispersion of device performance. Finally, possible correlation of the anode quasi-stationary polarizations and COD removal underlined the possibility to perform the instantaneous monitoring of the degradation process using flow MFCs. Future studies should be focused on device geometry and electrode materials, as well as better understanding the EET process for the utilized halotolerant bacterial species to maximize bioelectrochemical performance and develop self-powered 


\section{hypersaline microbial biosensor with improved sensitivity.}

\section{References}

[1] O. Lefebvre, R. Moletta, Water Res. 40 (2006) 3671-3682.

[2] UNESCO, Wastewater. The untapped resource, in: The United Nations World Water Development Report, 2017, pp. 1-12.

[3] Y.W. Cui, H.Y. Zhang, J.R. Ding, Y.Z. Peng, Sci. Rep. 6 (2016) 24825.

[4] M. Pernetti, L. Di Palma, Environ. Technol. 26 (2005) 695-703.

[5] R. Margesin, F. Schinner, Appl. Microbiol. Biotechnol. 56 (2001) 650-663.

[6] M.F. Edbeib, R.A. Wahab, F. Huyop, World J. Microbiol. Biotechnol. 32 (2016) 135.

[7] S. Le Borgne, D. Paniagua, R. Vazquez-Duhalt, J. Mol. Microbiol. Biotechnol. 15 (2008) 74-92.

[8] M. Grattieri, K. Beaver, E.M. Gaffney, S.D. Minteer, Faraday Discuss, 2019 https://doi.org/10.1039/c8fd00160j.

[9] C. Santoro, C. Arbizzani, B. Erable, I. Ieropoulos, J. Power Sources 356 (2017) 225-244.

[10] L. Shi, H. Dong, G. Reguera, H. Beyenal, A. Lu, J. Liu, H.Q. Yu, J.K. Fredrickson, Nat. Rev. Microbiol. 14 (2016) 651-662.

[11] G. Pankratova, L. Gorton, Curr. Opin. Electrochem. 5 (2017) 193-202.

[12] Y. Xiao, F. Zhao, Curr. Opin. Electrochem. 4 (2017) 206-211.

[13] A. Kumar, L.H.-H. Hsu, P. Kavanagh, F. Barrière, P.N.L. Lens, L. Lapinsonnière, J.H. Lienhard V, U. Schröder, X. Jiang, D. Leech, Nat. Rev. Chem. 1 (2017).

14] M. Grattieri, K. Hasan, S.D. Minteer, ChemElectroChem 4 (2017) 834-842.

[15] M. Grattieri, D.P. Hickey, B. Alkotaini, S.J. Robertson, S.D. Minteer J. Electrochem. Soc. 165 (2018) H251-H254.

[16] M. Grattieri, S.D. Minteer, ACS Sens. 3 (2018) 44-53.

[17] O. Lefebvre, Z. Tan, S. Kharkwal, H.Y. Ng, Bioresour. Technol. 112 (2012) $336-340$.

[18] R. Rousseau, X. Dominguez-Benetton, M.-L. Délia, A. Bergel, Electrochem. Commun. 33 (2013) 1-4.

[19] R. Rousseau, C. Santaella, W. Achouak, J.-J. Godon, A. Bonnafous, A. Bergel, M.L. Délia, ChemElectroChem 1 (2014) 1966-1975.

[20] R. Rousseau, C. Santaella, A. Bonnafous, W. Achouak, J.J. Godon, M.L. Delia, A. Bergel, Bioelectrochemistry 112 (2016) 24-32.

[21] O. Monzon, Y. Yang, C. Yu, Q. Li, P.J.J. Alvarez, Environ. Chem. 12 (2015)
293-299.

[22] M. Miyahara, A. Kouzuma, K. Watanabe, Bioresour. Technol. 218 (2016) 674-679.

[23] M. Grattieri, S.D. Minteer, Bioelectrochemistry 120 (2018) 127-137.

[24] M. Grattieri, Z. Rhodes, D.P. Hickey, K. Beaver, S.D. Minteer, ACS Catal. 9 (2019) 867-873.

[25] M. Grattieri, M. Suvira, K. Hasan, S.D. Minteer, J. Power Sources 356 (2017) 310-318.

[26] M. Grattieri, N.D. Shivel, I. Sifat, M. Bestetti, S.D. Minteer, ChemSusChem 10 (2017) 2053-2058.

[27] B. Alkotaini, S. Tinucci, S.J. Robertson, K. Hasan, S.D. Minteer, M. Grattieri, Chembiochem 19 (2018) 1162-1169.

[28] I. Satar, W.R.W. Daud, B.H. Kim, M.R. Somalu, M. Ghasemi, Energy 139 (2017) $1188-1196$.

[29] C. Santoro, K. Artyushkova, S. Babanova, P. Atanassov, I. Ieropoulos, M. Grattieri, P. Cristiani, S. Trasatti, B. Li, A.J. Schuler, Bioresour. Technol. 163 (2014) 54-63.

[30] I. Merino-Jimenez, C. Santoro, S. Rojas-Carbonell, J. Greenman, I. Ieropoulos, P. Atanassov, Catalysts 6 (2016) 127

[31] R. Rousseau, M. Rimboud, M.L. Delia, A. Bergel, R. Basseguy, Bioelectrochemistry 106 (2015) 97-104.

[32] Z. Ghasemi Naraghi, S. Yaghmaei, M.M. Mardanpour, M. Hasany, Electrochim. Acta 180 (2015) 535-544.

[33] M. Miyahara, A. Kouzuma, K. Watanabe, Amb. Express 5 (2015) 34.

[34] V.G. Paul, S.D. Minteer, B.L. Treu, M.R. Mormile, Environ. Technol. 35 (2014) 1003-1011.

[35] P. Roustazadeh Sheikhyousefi, M. Nasr Esfahany, A. Colombo, A. Franzetti, S.P. Trasatti, P. Cristiani, Appl. Energy 192 (2017) 457-465.

[36] B. Erable, R. Lacroix, L. Etcheverry, D. Feron, M.L. Delia, A. Bergel, Bioresour, Technol. 142 (2013) 510-516.

[37] O. Monzon, Y. Yang, J. Kim, A. Heldenbrand, Q. Li, P.J.J. Alvarez, Biochem. Eng. J. 117 (2017) 87-91.

[38] N. Liu, A.B. Charrua, C.H. Weng, X. Yuan, F. Ding, Bioresour. Technol. 198 (2015) 55-62.

[39] C.S. Chuang, M.K. Wang, C.H. Ko, C.C. Ou, C.H. Wu, Bioresour. Technol. 99 (2008) 954-958.

[40] J.P. Badalamenti, R. Krajmalnik-Brown, C.I. Torres, mBio 4 (2013) e00144-00113. 